\title{
Ultrasound Guidance and Flexible Fiberoptic Bronchoscopy Guidance in Percutaneous Dilatational Tracheostomy
}

\author{
Mohamed Hamdy Elghotmy* \\ Department of Anaesthesia, Intensive care \& and Pain Management, Mistry of Health, Egypt
}

Submission: October 22, 2019; Published: November 12, 2019

*Corresponding author: Mohamed Hamdy Elghotmy, Department of Anaesthesia, Intensive care \& and Pain Management, Mistry of Health, Shebin ElKom City, Menoufia governorate, Egypt

\begin{abstract}
Objective: to compare between the ultrasound guidance and flexible fiberoptic bronchoscopy guidance in percutaneous dilatational tracheostomy.

Subjects and Methods: The present study was carried out on 30 mechanically ventilated patients, admitted to different intensive care units of the Benha University Hospitals for whom elective tracheostomy was indicated. Patients were randomized into two groups: Group I: Included 15 patients for whom ultrasound guided percutaneous dilatational tracheostomy was done. Group II: Included 15 patients for whom fiberoptic bronchoscopy guided percutaneous dilatational tracheostomy was done.
\end{abstract}

Results: After 5 and 10 minutes from the onset of the procedure mean arterial blood pressure increased significantly in patients of group II where $p$ values were 0.044 and 0.025 . There was no significant difference in arterial carbon dioxide tension before the procedure ( $p=0.463)$ while it was significantly higher in group II after the procedure $(\mathrm{p}<0.001)$. Regarding immediate complications, no patients in both groups suffered from hypoxia. patients from group II suffered from hypercapnia which was significantly higher than group I in which no patients suffered from hypercapnia ( $\mathrm{p}=0.017)$.

Conclusions: Percutaneous dilatational tracheostomy is a bedside safe procedure with low rate of complications. Bronchoscopic guidance during PDT offers the best vision decreasing the need for multiple punctures and the risk of misdirection or false passage of the tube. Ultrasound is a promising less invasive method to guide the percutaneous tracheostomy procedure. Doppler examination of the neck can help decreasing the rate of bleeding during the procedure.

Keywords: Doppler examination; Bronchoscopic guidance; Percutaneous Dilatational Tracheostomy Ultrasound

\section{Introduction}

Tracheostomy is one of the oldest known surgical procedures that is now frequently per formed in Intensive Care Units (ICUs) in order to facilitate weaning from mechanical ventilation, reduce anatomical dead space, avoid laryngeal injury caused by prolonged intubation and aid in management of tracheobronchial and pulmonary secretions [1,2]. Percutaneous dilatational tracheostomy (PDT) is now a commonly per formed bedside procedure in the Intensive Care Unit. Several studies have demonstrated that PDT is a safe and cost-effective alternative to open, surgical tracheostomy $[3,4,5]$. In the study of Byhahn et al. [1] introduced a kit for PDT where the multiple dilator s of ciaglia's or iginal kit were replaced with a sharply tapered single dilator that has a hydrophilic coating and looks like a rhino's horn. Thus, the name blue rhino. Percutaneous dilatational tracheostomy (PDT) holds a number of per i-operative complications like hemorrhage, tube obstruction or displacement, pneumothorax, pneumo-mediastinum, aspiration, posterior tracheal wall lesion, fracture of tracheal rings, false passage, difficult tube placement, and subcutaneous emphysema [6,7]. A lot of assisting tools have long been used to facilitate guidance during percutaneous tracheostomy and hence reducing the incidence of these perioperative complications. These include ultrasound (US) imaging of the neck, light wand for trans-illumination of the soft tissues of the neck, and flexible fiberoptic bronchoscopy, other tools have been used to prevent hypoventilation during the procedure such as the laryngeal mask airway (LMA) $[8,9,10]$. This study 
was designed to compare between the ultrasound guidance and flexible fiberoptic bronchoscopy guidance in percutaneous dilatational tracheostomy.

\section{Subjects and Methods}

The present study was carried out on 30 mechanically ventilated patients, admitted to different intensive care units of the Benha University Hospitals for whom elective tracheostomy was indicated. Patients were randomized using the closed envelope method: into two groups:

a) Group I: Included 15 patients for whom ultrasound guided percutaneous dilatational tracheostomy was done.

b) Group II: Included 15 patients for whom fiberoptic bronchoscopy guided percutaneous dilatational tracheostomy was done.

\section{Ethical consideration}

The study was approved by the ethical committee of Benha Faculty of Medicine and an informed consent obtained from all patients before the study was commenced.

\section{Selection Criteria for the Patients}

The subjects included in this study were selected according to inclusion and exclusion criteria.

\section{Inclusion criteria}

patients for whom ultrasound and flexible fiberoptic bronchoscopy guided percutaneous dilatational tracheostomy.

\section{Exclusion criteria}

Age under 18 years, Coagulation disorder s (Platelet count $<50,000$ per mm3, INR $>1.3$, activated, partial thromboplastin time (APTT) $>50$ ). Infection at the puncture site, Emergency tracheostomy, Marked anatomic abnormalities of the trachea or cervical region.

\section{Preoperative}

Evaluation of each patient included full history taking, revision of all laboratory investigations and full clinical examination. All conscious patients received sedation using propofol and fentanyl with local infiltration of one percent lidocaine. Sedation was tit rated to obtain score 4-5 on Ramsay Sedation Scale (RSS). 100\% oxygen was applied to the patient for 30 minutes immediately prior to the procedure in order to prevent intra-operative hypoxia. An arterial cannula was inserted for all patients. [11] The Cook Ciaglia Blue Rhino® G2 (Cook Medical Inc., Bloomington, IN, USA) single stage dilator percutaneous tracheostomy kit was used. Continuous monitoring of ECG, arterial blood pressure and pulse oximetry was performed [12].

\section{Group N}

Tracheal and pre-tracheal anatomy was examined using palpation as well as the ultrasound. The ultrasound was used to confirm that the first tracheal ring was clearly visible above the sternal notch with the neck in the anticipated position for the tracheostomy. For morbidly obese patients the ultrasound was used to estimate the thickness of soft tissue between the skin and the trachea at the level of the second tracheal ring, as well as the internal diameter of the trachea itself at that level, with the head in the neutral position, in order to assess the need for an extended-length tracheostomy tube and the most appropriate size of tracheostomy tube [13]. ASonosite M-Turbo ${ }^{\circledR}$ (SonoSite Inc., Bothell, WA, USA) point-of-care ultrasound machine was used, with a 10 to $5 \mathrm{MHz}$ linear array probe and a sterile sheath. The mode of imaging was set to maximal resolution and depth of imaging adjusted to keep the trachea just within the screen [14]. After achieving the targeted level of sedation, the endotracheal tube was withdrawn under direct laryngoscopic vision until the cuff was positioned immediately inferior to the vocal cords. Transverse/axial (rather than longitudinal/sagittal) real-time imaging of the trachea was performed to permit clear visualization of the needle path up to the midline of the anterior wall of the trachea. The point of tracheal puncture was selected using the following criteria on sonographic imaging: below the first tracheal ring but above the fifth tracheal ring and no vascular structure in the path of the needle.

\section{Group ח}

The same technique was used except the set PEEP on the ventilator was discontinued. The tracheal suction was done thoroughly by the help of the flexible fiberoptic bronchoscope (Pentax Ltd, U.K. connected to an external screen). The choice of site of intended skin incision and then tracheal puncture was helped by the appearance of endoscopic indentation of the anterior tracheal wall on gentle pressure by the finger of the operator and by trans-illumination. ETT withdrawal was done under the visual control of the bronchoscope. All other steps were done by the visual control of the bronchoscope trying to avoid any structural injury $[15,16]$. In both groups Chest X-r ay was ordered immediately after the procedure and 48 hours after. A Fiberoptic Bronchoscopic examination through the tracheostomy tube was done 48 hours after the procedure and inspection of the tube and the wound was done daily for 7 days after the procedure. Facilities for surgical tracheostomy were ready in case of inability to introduce the tube or in case of major bleeding that requires conversion to surgical tracheostomy. These cases were to be excluded from the study.

\section{The following variables were measured}

a) Demographic characteristics of the patients: Age, Sex and Total body weight. Neck circumference, Duration of intubation before tracheostomy, Procedure Details (Duration of procedure starting from examination of the neck till the confirmation of tube position and Number of trials.

b) Hemodynamics: Mean arterial blood pressure and heart rate. Both were recorded before sedation, just before skin puncture and every 5 minutes till the end of the procedure. 
c) Blood gases parameters: Arterial oxygen tension and arterial carbon dioxide tension. (Before Start of dilatation and immediately after tube insertion).

\section{Complications were recorded including}

\section{Immediate}

Including Hypoxemia. (PaO2 $<60 \mathrm{mmHg}$ or saturation $<92 \%$ on FiO2 100\%), Hypercapnia. (PaCo2 > 45 mmHg), Misplacement or false passage into para-tracheal tissues, Minor bleeding; that stops with compression, Major bleeding; that causes hypotension, necessitates transfusion of at least 2 units of red cells, led to airway compromise, or required conversion to a surgical procedure to control it.

\section{Early: (within 48 hours)}

Pneumothorax/ pneumo-mediastinum, Subcutaneous emphysema, Hemorrhage; external or intra-tracheal, Poster orotracheal wall lesion and Tube obstruction or displacement.
Over dilatation of the stomal opening. The stoma dilatation is classified as adequate dilatation (stoma restricted to the anterior wall of the trachea), over dilatation (stoma margins extending to more than half of the anterior circumference), or near total transaction (when more than two-thirds of the tracheal circumference was dilated).

\section{Late: (after 7 days)}

Aspiration pneumonia and Wound infection.

\section{Statistical Analysis:}

Results were tabulated and statistically analyzed by using a personal computer using MICROSOFT EXCEL 2016 and SPSSv.21 (SPSS Inc., Chicago, IL, USA. Statistical analysis was done using: Descriptive: e.g. percentage (\%), mean and standard deviation. Analytical: that includes: Fisher's exact test, Chi-Squared $(\chi 2)$, One-way analysis of variance (ANOVA), and Tukey-Kramer test. A value of $P$ less than 0.05 was considered statistically significant.

\section{Results}

Table 1: Comparison between the studied groups regarding demographic data, Duration of intubation before tracheostomy, procedure and Number of trials.

\begin{tabular}{|c|c|c|c|c|c|c|}
\hline & \multicolumn{2}{|c|}{ Group I ( $(n=15)$} & \multicolumn{2}{|c|}{ Group II $(n=15)$} & \multirow[b]{2}{*}{$\mathbf{t}$} & \multirow[b]{2}{*}{$P$ value } \\
\hline & No. & $\%$ & No. & $\%$ & & \\
\hline Age/year & \multicolumn{2}{|c|}{$53.47 \pm 9.96$} & \multicolumn{2}{|c|}{$51.80 \pm 9.44$} & 0.471 & 0.642 \\
\hline Weight (kg) & \multicolumn{2}{|c|}{$84.27 \pm 7.74$} & \multicolumn{2}{|c|}{$85.67 \pm 8.30$} & 0.478 & 0.637 \\
\hline Neck circumference $(\mathrm{cm})$ & \multicolumn{2}{|c|}{$37 \pm 4.21$} & \multicolumn{2}{|c|}{$37.13 \pm 4.44$} & 0.084 & 0.933 \\
\hline Duration of intubation before tracheostomy (days) & \multicolumn{2}{|c|}{$12.13 \pm 2.80$} & \multicolumn{2}{|c|}{$12.53 \pm 2.97$} & 0.379 & 0.707 \\
\hline Duration of procedure (min.) & \multicolumn{2}{|c|}{$10.20 \pm 3.05$} & \multicolumn{2}{|c|}{$10.73 \pm 1.79$} & 0.584 & 0.565 \\
\hline Sex & & & & & $x^{2}$ & $\mathrm{P}$ \\
\hline Male & 8 & 53.3 & 9 & 60.0 & \multirow[b]{2}{*}{0.136} & \multirow[b]{2}{*}{0.713} \\
\hline Female & 7 & 46.7 & 6 & 40.0 & & \\
\hline Number of trials & & & & & $x^{2}$ & MCp \\
\hline One trial & 11 & 73.3 & 14 & 93.3 & & \\
\hline More than one Trial & 4 & 20.0 & 1 & 6.7 & 2.288 & 0.330 \\
\hline
\end{tabular}

t: student $\mathrm{t}$ teat,

X2: Chi square test

*: Statistically significant at $p$ value 0.05

Table 2: Comparison between the studied groups according to heart rate changes (beats $/ \mathrm{min}$ ).

\begin{tabular}{|c|c|c|c|c|c|}
\hline \multirow{2}{*}{} & \multicolumn{5}{|c|}{ Heart rate (beats/min) } \\
\cline { 2 - 6 } & Before sedation & After sedation & At 0 minutes & At 5 minutes & At 10 minutes \\
\hline Group I & & & & 68.0 & 71.0 \\
\hline Min. & 72.0 & 68.0 & 67.0 & 112.0 & 115.0 \\
\hline Max. & 126.0 & 114.0 & 110.0 & 84.93 & 87.20 \\
\hline Mean & 92.13 & 85.07 & 84.33 & 12.34 & 11.50 \\
\hline \pm SD & 14.19 & 12.50 & 11.76 & & 76.0 \\
\hline Group II & & & & 112.0 & 82.0 \\
\hline Min. & 69.0 & 66.0 & 67.0 & & 116.0 \\
\hline Max. & 105.0 & 98.0 & 97.0 & & \\
\hline
\end{tabular}




\section{Journal of Anesthesia \& Intensive Care Medicine}

\begin{tabular}{|c|c|c|c|c|c|}
\hline Mean & 86.53 & 83.67 & 84.07 & 94.0 & 97.13 \\
\hline \pm SD & 10.37 & 9.77 & 9.63 & 10.41 & 10.54 \\
\hline $\mathrm{T}$ & 1.234 & 0.342 & 0.068 & $2.174^{*}$ & $2.466^{*}$ \\
\hline $\mathrm{P}$ & 0.227 & 0.735 & 0.946 & $0.038^{*}$ & $0.020^{*}$ \\
\hline
\end{tabular}

$t, p: t$ and $p$ values for Student t-test for comparing between the two studied groups

*: Statistically significant at $p$ value 0.05

Table 3: Comparison between the studied groups regarding Mean arterial blood pressure $(\mathrm{mmHg})$.

\begin{tabular}{|c|c|c|c|c|c|}
\hline \multicolumn{6}{|c|}{ Mean arterial blood pressure ( $\mathrm{mmHg}$ ) } \\
\hline & Before sedation & After sedation & At 0 minutes & At 5 minutes & At 10 minutes \\
\hline \multicolumn{6}{|c|}{ Group I } \\
\hline Min. & 86 & 81 & 79 & 79 & 82 \\
\hline Max. & 130 & 123 & 127 & 123 & 124 \\
\hline Mean & 101.8 & 96.73 & 96.6 & 96.67 & 98.47 \\
\hline$\pm \mathrm{SD}$ & 12.9 & 11.47 & 12.95 & 12.43 & 11.41 \\
\hline \multicolumn{6}{|c|}{ Group II } \\
\hline Min. & 82 & 79 & 74 & 86 & 89 \\
\hline Max. & 128 & 121 & 122 & 131 & 132 \\
\hline Mean & 100.4 & 94.27 & 95.93 & 106.2 & 108.67 \\
\hline$\pm \mathrm{SD}$ & 13.09 & 11.25 & 13.73 & 12.35 & 12.24 \\
\hline $\mathrm{T}$ & 0.295 & 0.595 & 0.137 & $2.107^{*}$ & $2.361^{*}$ \\
\hline $\mathrm{P}$ & 0.77 & 0.557 & 0.892 & $0.044^{*}$ & $0.025^{*}$ \\
\hline
\end{tabular}

Table 4: Comparison between the two studied groups according to Arterial oxygen tension $\left(\mathrm{PaO}_{2}\right)$ and Arterial carbon dioxide tension $\left(\mathrm{P}_{\mathrm{a}} \mathrm{CO}_{2}\right)$.

\begin{tabular}{|c|c|c|c|c|}
\hline & \multicolumn{4}{|c|}{ Arterial oxygen tension $\left(\mathrm{P}_{\mathrm{a}} \mathrm{O}_{2}\right)$} \\
\hline & \multicolumn{2}{|c|}{ Group I } & \multicolumn{2}{|c|}{ Group II } \\
\hline & Before dilatation & After tube insertion & Before dilatation & After tube insertion \\
\hline Min. & 170.0 & 167.0 & 192.0 & 152.0 \\
\hline Max. & 419.0 & 414.0 & 375.0 & 343.0 \\
\hline Mean & 264.87 & 250.33 & 263.80 & 233.67 \\
\hline$\pm \mathrm{SD}$ & 65.38 & 63.81 & 48.99 & 52.79 \\
\hline $\mathrm{t}_{1}\left(\mathrm{p}_{1}\right)$ & \multicolumn{2}{|c|}{$7.053(<0.001)$} & \multicolumn{2}{|c|}{$10.777(<0.001)$} \\
\hline $\mathrm{t}_{2}\left(\mathrm{p}_{2}\right)$ & & & $0.051(0.960)$ & $0.779(0.442)$ \\
\hline \multicolumn{5}{|c|}{ Arterial carbon dioxide tension $\left(\mathrm{P}_{\mathrm{a}} \mathrm{CO}_{2}\right)$} \\
\hline & \multicolumn{2}{|c|}{ Group I } & \multicolumn{2}{|c|}{ Group II } \\
\hline & Before dilatation & After tube insertion & Before dilatation & After tube insertion \\
\hline Min. & 26.0 & 25.0 & 26.0 & 38.0 \\
\hline Max. & 41.0 & 41.0 & 39.0 & 54.0 \\
\hline Mean & 34.20 & 34.93 & 33.07 & 45.0 \\
\hline$\pm \mathrm{SD}$ & 4.55 & 4.67 & 3.75 & 4.78 \\
\hline $\mathrm{t}_{1}\left(\mathrm{p}_{1}\right)$ & $2.048(0.060)$ & $13.150(<0.001)$ & & \\
\hline $\mathrm{t}_{2}\left(\mathrm{p}_{2}\right)$ & & & $0.744(0.463)$ & $5.836(<0.001)$ \\
\hline
\end{tabular}

Table 5: Comparison between the two studied groups according to Immediate complications and Wound infection.

\begin{tabular}{|c|c|c|c|c|c|c|}
\hline & \multicolumn{2}{|c|}{ Group I (n = 15) } & \multicolumn{2}{|c|}{ Group II (n = 15) } & \multirow{2}{*}{$\mathbf{X}^{2}$} & \multirow{2}{*}{ FEp } \\
\cline { 2 - 6 } & No. & \% & No. & \% & & \\
\hline Immediate complications & & & & & - & - \\
\hline -Hypoxia & 0 & 0.0 & 0 & 0.0 & $7.500^{*}$ & $0.017^{*}$ \\
\hline -Hypercapnia & 0 & 0.0 & 6 & 40.0 & & \\
\hline
\end{tabular}


Journal of Anesthesia \& Intensive Care Medicine

\begin{tabular}{|c|c|c|c|c|c|c|}
\hline -False passage & 2 & 13.3 & 0 & 0.0 & 2.916 & 0.483 \\
\hline -Minor bleeding & 1 & 6.7 & 4 & 26.7 & 2.160 & 0.330 \\
\hline -Major bleeding & 0 & 0.0 & 0 & 0.0 & - & - \\
\hline -Subcutaneous emphysema & 0 & 0.0 & 0 & 0.0 & - & - \\
\hline Wound infection & & & & & 1.154 & \\
\hline Yes & 3 & 20.0 & 1 & 6.7 & & \\
\hline No & 12 & 80.0 & 14 & 93.3 & & \\
\hline
\end{tabular}

\section{X2: Chi square test}

FE: Fisher Exact for Chi square test

\section{*: Statistically significant at $\mathrm{p}$ t0.05}

The current study showed that no significant difference was observed between the two groups regarding age $(p=0.642)$, Weights $(p=0.637)$, sex $(p=0.713)$ and Neck circumference $(p=0.933)$, duration of intubation before tracheostomy $(p=0.707)$, duration of the procedure ( $\mathrm{p}=0.565)$. also, in group i: 3 patients needed 2 trials while 1 patient needed 3 trials while in Group II only one patient needed 2 trials. There was no statistically significant difference observed between the two groups $(\mathrm{MCp}=0.330)$, (Table 1). Also, comparing heart rate changes in both groups showed no significant difference at the before sedation, immediately after sedation and at 0 minutes from the onset of the procedure ( $p=0.227,0.735$ and 0.946 respectively). After 5 and 10 minutes from the onset of the procedure heart rate increased significantly in patients of group II where $p$ values were 0.035 and 0.20 respectively, (Table 2). Furthermore, comparing mean arterial blood pressure changes in both groups showed no significant difference at the before sedation, immediately after sedation and at 0 minutes from the onset of the procedure $(\mathrm{p}=0.770,0.557$ and 0.892 respectively). After 5 and 10 minutes from the onset of the procedure mean arterial blood pressure increased significantly in patients of group II where $\mathrm{p}$ values were 0.044 and 0.025 , (Table $3)$. Also, Comparing the arterial oxygen tension in both groups showed that there was no significant difference the procedure nor after the procedure $(p=0.960$ and 0.442$)$. Comparing the two groups showed that there was no significant difference in arterial carbon dioxide tension before the procedure $(\mathrm{p}=0.463)$ while it was significantly higher in group II after the procedure $(\mathrm{p}<0.001)$, (Table 4). Regarding immediate complications, no patients in both groups suffered from hypoxia. patients from group II suffered from hypercapnia which was significantly higher than group I in which no patients suffered from hypercapnia $(\mathrm{p}=0.017)$. Two patients from group I suffered from false passage versus 0 patients in group II which was statistically insignificant $(\mathrm{p}=0.483)$. One patient in group I suffered from minor bleeding versus four patients in group II. Again, it was statistically insignificant $(\mathrm{p}=0.330)$. No patients in both groups suffered from major bleeding or subcutaneous emphysema. Three patients in Group I suffered from wound infection versus only one patient in group II. It was of no significant difference (Table 5).

\section{Discussion}

In the present study; both groups were matched as regards age, sex and body weight. There was also no statistically significant difference between the two groups regarding neck circumference or the duration of intubation before tracheostomy. Also, both groups were comparable regarding the duration of the procedure and the number of trials, the latter is probably due to the small sample size as in ultrasound guided group more cases (4 cases) required reidentification of puncture site or redirection of the guide wire than the fiberoptic bronchoscopy guided group. Similar to the results of Guinot et al. [17] found that the duration of ultrasound guided PDT was of a median time of 10 minutes in both obese and non-obese groups. Also, Ambesh et al. [11] compared between PDT using CBR and Gr iggs' guide wire dilating forceps (GWDF) stating the average time needed for CBR technique guided by bronchoscopy was $7.5 \pm 2.5$ minutes which was not much quicker than the finding in the present study. In contrast to the results of Ravi and Vijay [18] documented statistically significant shorter duration of procedure in the US guided PDT than in bronchoscopy guided PDT. Also, a smaller number of punctures with US guided PDT but the later was statistically insignificant. This is probably because all the participants in their study received specialized training in ultrasonography of the neck with radiologists prior to participating in the study. Regarding hemodynamic changes there was no significant elevation of heart rate nor mean arterial blood pressure in group I at 0 and 5 minutes after onset of the procedure comparing it to the measurements after sedation. But they were both slightly elevated at 10 minutes or at the end of the procedure. In Group II, both heart rate and mean arterial blood pressure were significantly increased at 5 and 10 minutes from the onset of the procedure. The increase in hemodynamic measurements was higher in group II than in group I in a statistically significant way at both 5 and 10 minutes from the onset of the procedure. This is probably due to the associated hypercapnia noticed in group II or due to the stress of the bronchoscopy procedure itself. Somers et al., [19] in their physiological study showed that hypercapnia causes increase in heart rate and arterial blood pressure mediated by an increase of sympathetic system activity. Also, Davies et al. [20] stated dedicated for the cardiovascular changes related to fiberoptic bronchoscopy that bronchoscopy procedure is related to immediate elevation of both systolic and diastolic blood pressure that resolved immediately after the withdrawal of the bronchoscope. While Ambesh et al. [21] reported that two out of his thirty patients undergoing PDT using Ciaglia blue rhino (CBR) kit suffered from sudden decrease in arterial blood pressure 
(systolic blood pressure $<80 \mathrm{mmHg}$ ) with 3-6 ventricular ectopic beats during tracheal dilation that improved after withdrawal of the CBR, we actually did not notice this in the present study.

As regards arterial blood gases, a statistically significant decrease in $\mathrm{PaO} 2$ was noted in both groups but with no significant difference between them. No case suffered from hypoxia $(\mathrm{PaO} 2<60 \mathrm{mmHg}$ or $\mathrm{SO} 2<92 \%)$. Similarly, Hassanin et al. [23] monitored SpO2, there was significant decrease during the procedure guided by bronchoscopy but again when comparing it to traditional landmarks technique there was no statistically significant difference between two groups. On the contrary, Ravi and Vijay [22] reported 4 patients out of 36 had bronchoscopic guided PDT suffered from temporary desaturation comparing it to nil patients in the ultrasound guided group which was statistically significant. Regarding the arterial carbon dioxide tension, Group I did not show a statistically significant increase in PaCO2. On the contrary, groups II showed statistically significant elevation of PaCO2 after tube insertion comparing it to its level before start of dilatation $[23,24]$. The overall number of patients who suffered from hypercapnia were 6 patients in group II versus no patients in group I probably due to hypoventilation associated with the bronchoscopy procedure. In agreement with the present study, Reilly et al. [9] reported in a study dedicated for the hypercapnia phenomenon associated with percutaneous dilatational tracheostomy that there was significant elevation in PaCO2 levels in patients had bronchoscopy guided PDT versus patients had Doppler guided PDT and patients received conventional surgical tracheostomy. In a different study, Escarment et al. [25] reported significant increase in $\mathrm{PaCO} 2$ when using the endoscopic guidance without significant change in the $\mathrm{SaO} 2 / \mathrm{FiO} 2$ ratio. This goes with the findings of our study. In the present study, only one patient in group 1 had minor bleeding versus 4 cases in group II. Bleeding was stopped mechanically by compression. Though it was statistically insignificant, it strongly suggests the ability of decreasing the rate of bleeding during the procedure via doppler scanning of the neck and incision site by ultrasound prior to the beginning of the procedure. No cases in both groups suffered from major bleeding. Consistent with the present study, Ravi and Vijay [18] reported in their study that 12 patients (out of 36) in the bronchoscopy guided group had minor bleeding (defined as bleeding less than $5 \mathrm{ml}$ ) while 4 patients from the same group suffered from major bleeding $(<50 \mathrm{ml})$ versus no patients in the ultrasound guided group. Similarly, Rudas et al. [26] reported decreased number of minor bleeding in case of ultrasound guidance when comparing it to the traditional landmarks' method (3 out of 25 patients in US guided group versus 7 patients in blind group).

Within 48 hours of the procedure, no cases in both groups suffered from pneumothorax/pneumo-mediastinum, subcutaneous emphysema, hemorrhage; external or intratracheal, posterior tracheal wall lesion, tube displacement or over dilatation of the stomal opening. In agreement with the finding of Beiderlinden et al. [27] showed that after 24 hours from bronchoscopy guided procedure no patients developed pneumothorax, extra tracheal bleeding or posterior tracheal wall lesion and only two patients (1.5\%) had moderate intratracheal bleeding. Similarly, Rajajee et al. [12] al observed no complications detected either by bronchoscopy or by chest $\mathrm{x}$ ray during their study to assess the feasibility of the ultrasound guided PDT. After seven days of the procedure 3 cases of group I showed wound infection versus only one case of group II. It was statistically insignificant. And it was resolved via topical antibiotic preparations and local care of the wound. Hagiya et al. [28] studied the effect of prophylactic antibiotic administration on preventing wound infection in PDT. They observed only 7 patients out of 297 developed wound infection. (5 in the no antibiotic group and only 2 in the antibiotic group). Also, Ravi et al. [22] agreed with the present study as they observed no significant difference in the rate of stomal infection after PDT guided by either ultrasound or bronchoscopy.

\section{Conclusion}

Percutaneous dilatational tracheostomy is a bedside safe procedure with low rate of complications. Bronchoscopic guidance during PDT offers the best vision decreasing the need for multiple punctures and the risk of misdirection or false passage of the tube. Bronchoscopy holds the risk of hypercapnia with elevated hemodynamic measurements. Ultrasound is a promising less invasive method to guide the percutaneous tracheostomy procedure. Doppler examination of the neck can help decreasing the rate of bleeding during the procedure.

\section{References}

1. Byhahn C, Lischke V, Halbig S, Scheifler G, Westphal K (2000) Ciaglia blue rhino: a modified technique for percutaneous dilatation tracheostomy. Technique and early clinical results. Anaesthesist 49(3): 202-206.

2. Fikkers BG (2004) Percutaneous tracheostomies on the intensive care unit: UB Nijmegen [Host]

3. Delaney A, Bagshaw SM, Nalos M (2006) Percutaneous dilatational tracheostomy versus surgical tracheostomy in critically ill patients: a systematic review and meta- analysis. Crit Care 10(2): 55.

4. Heikkinen M, Aarnio P, Hannukainen J (2000) Percutaneous dilational tracheostomy or conventional surgical tracheostomy? Crit Care Med 28(5): 1399-1402.

5. Freeman BD, Isabella K, Cobb JP, Boyle WA, $3^{\text {rd }}$, Schmieg RE, et al. (2001) A prospective, randomized study comparing percutaneous with surgical tracheostomy in critically ill patients. Crit Care Med 29(5): 926-930.

6. van Heurn LW, Theunissen PH, Ramsay G, Brink PR (1996) Pathologic changes of the trachea after percutaneous dilatational tracheotomy. Chest 109(6): 1466-1469.

7. Walz MK, Schmidt U (1999) Tracheal lesion caused by percutaneous dilatational tracheostomy--a clinico-pathological study. Intensive Care Med 25(1): 102-105.

8. Kollig E, Heydenreich U, Roetman B, Hopf F, Muhr G (2000) Ultrasound and bronchoscopic controlled percutaneous tracheostomy on trauma ICU. Injury 31(9): 663-668. 
9. Reilly PM, Sing RF, Giberson FA, Anderson HL $3^{\text {rd }}$, Rotondo MF et al. (1997) Hypercarbia during tracheostomy: a comparison of percutaneous endoscopic, percutaneous Doppler, and standard surgical tracheostomy. Intensive Care Med 23(8): 859-864.

10. Gregersen P, Oestergaard M, Carl P (2004) Use of Laryngeal Mask Airway (LMA) during Percutaneous Dilation Tracheostomy (PDT). Eur J Anaesthesiol 21: 178.

11. Ambesh SP, Pandey CK, Srivastava S, Agarwal A, Singh DK (2002) Percutaneous tracheostomy with single dilatation technique: a prospective, randomized comparison of Ciaglia blue rhino versus Griggs' guidewire dilating forceps. Anesth Analg 95(6): 1739-1745.

12. Rajajee V, Fletcher JJ, Rochlen LR, Jacobs TL (2011) Real-time ultrasound-guided percutaneous dilatational tracheostomy: a feasibility study. Crit Care 15(1): 67.

13. Szeto C, Kost K, Hanley JA, Roy A, Christou N (2010) A simple method to predict pretracheal tissue thickness to prevent accidental decannulation in the obese. Otolaryngol Head Neck Surg 143(2): 223229.

14. Adhikari S, Zeger W, Schmier C, Crum T, Craven A, et al. (2011) Pilot Study to Determine the Utility of Point of care Ultrasound in the Assessment of Difficult Laryngoscopy. Academic Emergency Medicine 18(7): 754-758.

15. Lindholm CE, Ollman B, Snyder JV, Millen EG, Grenvik A (1978) Cardiorespiratory effects of flexible fiberoptic bronchoscopy in critically ill patients. Chest 74(4): 362-368.

16. Ragab A, Khan R (2014) Fiberoptic-guided percutaneous dilatational tracheostomy versus surgical tracheostomy for intensive care ventilated patients. Egypt J Cardiothoracic Anesth 8(1): 27-32.

17. Guinot PG, Zogheib E, Petiot S, Marienne JP, Guerin AM, et al Ultrasound-guided percutaneous tracheostomy in critically ill obese patients. Crit Care 16(2): 40.

18. Ravi PR, Vijay MN (2015) Real time ultrasound-guided percutaneous tracheostomy: Is it a better option than bronchoscopic guided percutaneous tracheostomy? Med J Armed Forces India 71(2): 158164.

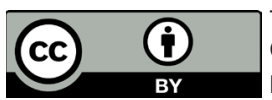

This work is licensed under Creative Commons Attribution 4.0 License

DOI: 10.19080/JAICM.2019.09.555775
19. Somers VK, Mark AL, Zavala DC, Abboud FM (1989) Contrasting effects of hypoxia and hypercapnia on ventilation and sympathetic activity in humans. J Appl Physiol 67(5): 2101-2106.

20. Davies L, Mister R, Spence DP, Calverley PM, Earis JE, et al. (1997) Cardiovascular consequences of fibreoptic bronchoscopy. Eur Respir J $10(3): 695-698$.

21. Ambesh SP (2010) Principles and practice of percutaneous tracheostomy. New Delhi, India: Jaypee Brothers Publishers.

22. Ravi PR, Vijay MN (2015) Real time ultrasound-guided percutaneous tracheostomy: Is it a better option than bronchoscopic guided percutaneous tracheostomy? Med J Armed Forces India 71(2): 158164.

23. Hassanin EG, Elgnady AA, El-Hoshy MS, Beshey BN, Abdelhady AM (2013) Fiberoptic bronchoscopic guidance in percutaneous dilational tracheotomy. Egyptian J Chest Dis Tuberc 62(3): 519-527.

24. Reilly PM, Sing RF, Giberson FA, Anderson HL $3^{\text {rd, }}$ Rotondo MF, et al. Hypercarbia during tracheostomy: a comparison of percutaneous endoscopic, percutaneous Doppler, and standard surgical tracheostomy. Intensive Care Med 23(8): 859-864.

25. Escarment J, Suppini A, Sallaberry M, Kaiser E, Cantais E, et al. (2000) Percutaneous tracheostomy by forceps dilation: report of 162 cases. Anaesthesia 55(2): 125-130.

26. Rudas M, Seppelt I, Herkes R, Hislop R, Rajbhandari D, et al. (2014) Traditional landmark versus ultrasound guided tracheal puncture during percutaneous dilatational tracheostomy in adult intensive care patients: a randomised controlled trial. Crit Care 18(5): 514.

27. Beiderlinden M, Karl Walz M, Sander A, Groeben H, Peters J (2002) Complications of bronchoscopically guided percutaneous dilational tracheostomy: beyond the learning curve. Intensive Care Med 28(1): 59-62.

28. Hagiya H, Naito H, Hagioka S, Okahara S, Morimoto N, et al. (2014) Effects of antibiotics administration on the incidence of wound infection in percutaneous dilatational tracheostomy. Acta Med Okayama 68(2): 57-62.

\section{Your next submission with Juniper Publishers will reach you the below assets}

- Quality Editorial service

- Swift Peer Review

- Reprints availability

- E-prints Service

- Manuscript Podcast for convenient understanding

- Global attainment for your research

- Manuscript accessibility in different formats

( Pdf, E-pub, Full Text, Audio)

- Unceasing customer service

Track the below URL for one-step submission

https://juniperpublishers.com/online-submission.php 